\title{
Highway Traffic Accident Influence Area Based on Vehicle Bypass Decision-Making Index
}

\author{
Zhenjun Zhu, ${ }^{1,2,3}$ Yang Lu, ${ }^{4}$ Jun Zeng, ${ }^{1,2,3}$ and Hongsheng Chen ${ }^{5}$ \\ ${ }^{1}$ Jiangsu Key Laboratory of Urban ITS, Southeast University, Si Pai Lou No. 2, Nanjing 210096, China \\ ${ }^{2}$ Jiangsu Province Collaborative Innovation Center of Modern Urban Traffic Technologies, Southeast University, \\ Si Pai Lou No. 2, Nanjing 210096, China \\ ${ }^{3}$ School of Transportation, Southeast University, Si Pai Lou No. 2, Nanjing 210096, China \\ ${ }^{4}$ Kunshan Transport Management Office, Hongqiao Road No. 109, Kunshan 215399, China \\ ${ }^{5}$ School of Architecture, Southeast University, Si Pai Lou No. 2, Nanjing 210096, China \\ Correspondence should be addressed to Zhenjun Zhu; zhuzhenjun@seu.edu.cn
}

Received 30 June 2016; Revised 20 October 2016; Accepted 23 January 2017; Published 26 February 2017

Academic Editor: Juan C. Cano

Copyright @ 2017 Zhenjun Zhu et al. This is an open access article distributed under the Creative Commons Attribution License, which permits unrestricted use, distribution, and reproduction in any medium, provided the original work is properly cited.

In order to reduce the impact of highway traffic accidents on surrounding road networks, accident influence area should be determined reasonably. According to the relationship between vehicle bypass decision-making index and threshold under accident condition, the vehicles' route choice behavior at upstream of the accident spot can be divided into two types: bypass and nonbypass. Under nonbypass condition, the method of using traffic wave theory was put forward to determine the upstream influence area. Under bypass condition, the total number of bypass vehicles is determined based on bypass decision-making index being greater than bypass threshold. Assignment algorithms based on routes were proposed. Using improved Logit model to get the selection probability and the traffic flow of each route, then traffic flow of surrounding links could be obtained. At last, the road network influenced by the accident could be determined by comparing with the level of service of each link under normal condition. The paper takes Beijing-Kunming highway as an example, and the results show that the road network formed by the influenced links was highway traffic accident influence area. Comparing with the actual survey results, correctness of the calculation method is verified. Therefore, the analytical method based on bypass decision-making is applicable to determining highway accident influence area.

\section{Introduction}

An accident causes part of highway lanes to close, which forms bottleneck. When vehicles from upstream and turning and merging into traffic flow arrive in accident links, congestion may make some vehicles bypass, which influences surrounding road network. Through identifying the influence area of highway traffic accidents and then determining the impact extent of traffic accidents and traffic organization area, the paper can provide important basic theories and methods for the evaluation of accident influence, the organization of emergency traffic, the promotion of accident processing efficiency, and the elimination of accidents' negative effects.

The existing studies on highway accident influence area mainly concentrate on determination of queue length and time-spatial diffusion of congestion and point out that it is significant to identify highway traffic accident influence area for reasonable traffic organization. Morales [1] proposed a deterministic queuing theory model using arrival-departure curve to estimate the total delay caused by events. The results were quite different from actual situation due to the fact that arrival rate and departure rate were assumed to be unchanged. Sheu et al. [2] proposed stochastic queuing model, which defined six random traffic state parameters based on lane-changing behavior to predict queue length caused by incidents. Newell $[3,4]$ proposed curve model of arrival-departure and cumulative flow share based on traffic wave theory to estimate highway traffic state. Lawson et al. [5] improved cumulative arrival-departure model to estimate time-spatial diffusion area of bottleneck links' congestion 
TABLE 1: Bypass decision-making influential factors under accident condition.

\begin{tabular}{|c|c|c|c|c|c|}
\hline Influential factors & Very large & Larger & General & Less & No influence \\
\hline Travel delay & $87 \%$ & $13 \%$ & 0 & 0 & 0 \\
\hline Distance & $17 \%$ & $14 \%$ & $33 \%$ & $32 \%$ & $4 \%$ \\
\hline Bypass costs & $8 \%$ & $15 \%$ & $49 \%$ & $18 \%$ & $10 \%$ \\
\hline Trip purpose & $12 \%$ & $15 \%$ & $23 \%$ & $32 \%$ & $18 \%$ \\
\hline Safety & $5 \%$ & $7 \%$ & $32 \%$ & $34 \%$ & $22 \%$ \\
\hline Comfort & $3 \%$ & $7 \%$ & $23 \%$ & $46 \%$ & $21 \%$ \\
\hline Weather condition & $7 \%$ & $13 \%$ & $23 \%$ & $45 \%$ & $12 \%$ \\
\hline
\end{tabular}

through tracking vehicles at the tail. Chien et al. [6] proposed a model to calculate traffic incidents' delay based on traffic wave theory. Sansò et al. [7, 8] evaluated the degree that urban traffic network efficacy was influenced by accidents based on modified static user-optimized equilibrium model. Engelson [9] used queuing theory and traffic flow wave theory to analyze influence area of upstream links and intersections caused by occasional traffic congestion. Cao et al. [10] proposed a traffic analysis model under accident condition based on traffic wave theory and analyzed timespatial influence area.

In summary, almost all the existing studies did not consider influential factors and thresholds of drivers' bypass decision-making, and discriminatory analysis of road network influence degree was relatively less. Based on route choice behavior of vehicles, influential factors of bypass decision-making and thresholds are analyzed through the questionnaire survey. Traffic wave theory is used to determine highway accident influence area under nonbypass condition. Considering the selection probability of a path is a function related to traffic flow, the paper develops an improved Logit model based on existing improved methods [11, 12], which is used to determine bypass probability and bypass traffic flow volume. Influenced links are determined through comparison with level of service (LOS, which reflects road traffic load status and service quality through the ratio of traffic flow and capacity $[13,14])$ variation under normal condition; the highway accident influence area is the road network formed by these influenced links.

\section{Vehicles Bypass Decision-Making Index and Thresholds on Highway}

2.1. Bypass Decision-Making Index Selection. Traffic bottlenecks are coming into being nearby the accident spot when accidents occur, and upstream traffic flow queues in front of the bottleneck link. Travel time of the accident link is divided into four parts: upstream travel time of the bottleneck link, queue waiting time in front of the bottleneck link, passing bottleneck link time, and downstream travel time of the bottleneck link [15]. Only travel times of queuing and bottleneck links are changing with time among the above four time periods; travel times of other links basically remain unchanged. Therefore, travel delays occur mainly in queuing and bottleneck links.
Bypass decision-making index is selected to analyze most concerned factors when drivers choose to bypass. Based on travellers' willingness and perception, factors of vehicles bypass decision-making on highway under accident conditions are analyzed through questionnaire survey, which includes revealed preference survey and stated preference survey. The survey site is located in Pucheng toll station on Beijing-Kunming highway; the authors hand out 500 questionnaires; 436 valid questionnaires are recycled. According to the survey, bypass decision-making influential factors are divided into five grades, as shown in Table 1 . Results show that travel delay of the accident link is the most important factor and most concerned by drivers. Therefore, travel delay is selected as bypass decision-making index.

2.2. Bypass Threshold Value. In general, drivers have a tolerable range about travel delay. When travel delay exceeds a certain level that cannot be tolerated, drivers choose to bypass. So tolerable travel delay boundary is selected as bypass threshold [16]. If travel delay satisfies certain distribution, bypass threshold can be replaced by the corresponding upper quantile according to a certain degree of confidence level. Assume random variable $r$ is travel delay of accident links and $F(r)$ is distribution function and take a confidence level $\alpha(0<\alpha<1)$; then, the bypass threshold could be expressed as follows:

$$
T=F_{\alpha} .
$$

Assume $D$ is the travel delay when a vehicle passes through accident links. If $D>T$, drivers queue to pass through the accident spot. If $D<T$, drivers will choose other paths to pass through.

Kishi’s Logit Price Sensitivity Measurement (KLP) $[17,18]$ is used to study bypass threshold. Based on survey data, calibration, and regression fitting of KLP model, distribution curve of acceptable bypass threshold for drivers is obtained, as shown in Figure 1.

According to $85 \%$ quantile, travel delay threshold is 31 min on Beijing-Kunming highway, which is clearly shown in Table 2.

\section{Traffic Accident Influence Area under Nonbypass Condition}

3.1. Queuing Vehicles Occupy the Total Length of Roads. If travel delay is less than bypass threshold, the upstream 


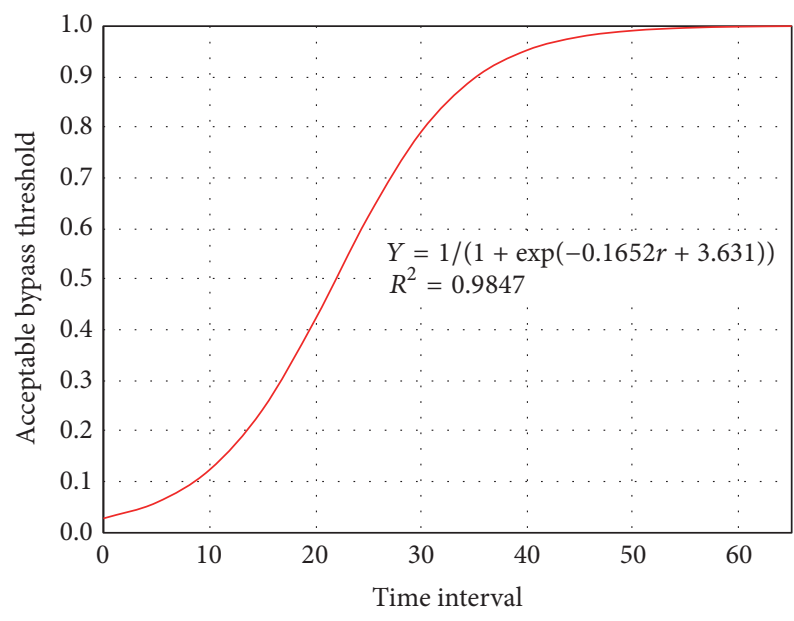

FIGURE 1: Distribution of vehicles' acceptable bypass threshold.

TABLE 2: Bypass threshold under accident condition on highway.

\begin{tabular}{lccc}
\hline $\begin{array}{l}\text { Quantile } \\
\text { value }\end{array}$ & $\begin{array}{c}\text { Bypass } \\
\text { threshold }\end{array}$ & $\begin{array}{c}\text { Quantile } \\
\text { value }\end{array}$ & $\begin{array}{c}\text { Bypass } \\
\text { threshold }\end{array}$ \\
\hline $50 \%$ & $23 \mathrm{~min}$ & $85 \%$ & $31 \mathrm{~min}$ \\
$70 \%$ & $27 \mathrm{~min}$ & $90 \%$ & $36 \mathrm{~min}$ \\
\hline
\end{tabular}

traffic flow does not bypass. For such situations, upstream influence area is determined by traffic wave theory. Assume that a traffic accident occurs on the basic link of highway, where upstream traffic demand is greater than actual capacity. Upstream traffic flow slows down and even stops in front of the accident spot and queuing wave is formed. When the accident is cleared, capacity is also resumed and upstream queuing vehicles start to form evanescent wave. The queue length caused by accident is relevant to traffic waves meeting situation at various accident development stages. Generation, dissemination, and meeting of traffic waves under noninterference condition are shown in Figure 2.

In Figure $2, t$ is the duration after the accident occurrence. $X_{b}$ is the distance from the accident spot. $t_{0}$ is the moment when accident ends. $t_{b}$ is the moment when queuing vehicles occupy the maximum link length. $t_{c}$ is the moment when evanescent wave passes through the accident spot. $U_{a}$ is stop wave at upstream of the accident spot. $U_{b}$ is start wave at upstream of the accident spot. $U_{c}$ is evanescent wave formed by the meeting of stop wave and start wave.

Queue length of accident links is related to generation and meeting situation of traffic waves. That is to say, stop wave $U_{a}$ and start wave $U_{b}$ are related to evanescent wave $U_{c}$. The equation is established as follows:

$$
U_{b}\left(t_{b}-t_{0}\right)=U_{a} t_{b}
$$

$t_{b}$ is obtained by (2), as show in (3):

$$
t_{b}=\frac{U_{b}}{U_{b}-U_{a}} \times t_{0} .
$$

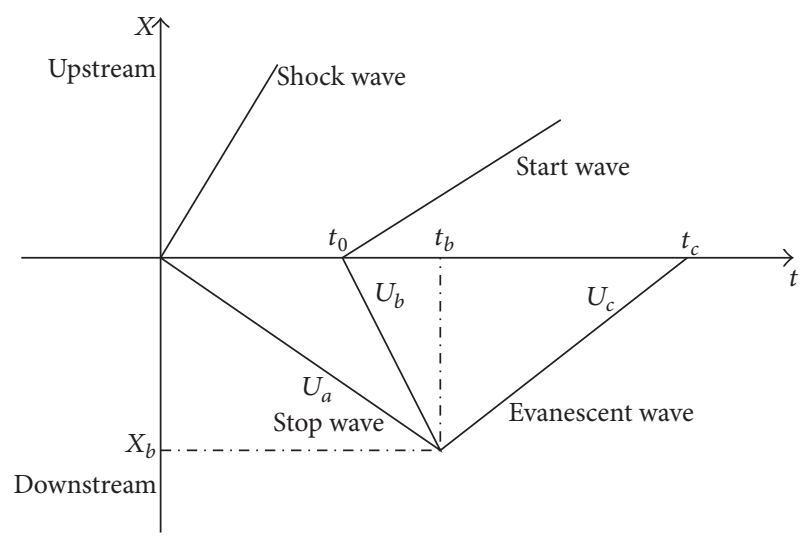

FIGURE 2: Situations of traffic waves' generation and meeting.

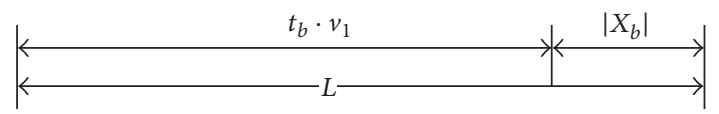

FIGURE 3: Highway traffic accident influence area under nonbypass condition.

$X_{b}$ is the total link length occupied by queuing vehicles, which can be calculated as in (4):

$$
X_{b}=U_{a} \times t_{b}=\frac{U_{a} U_{b}}{U_{b}-U_{a}} \times t_{0} .
$$

3.2. Influence Area Identification under Nonbypass Condition. Queues caused by accidents will always exist within the duration of highway traffic accident congestion. When the upstream vehicles reach the end of queues, queuing still continues. Therefore, arriving vehicles join into the queue and suffer congestion and are unable to reach destinations within the normal time. When queuing wave meets start wave, queues caused by accidents begin to dissipate gradually. Starting from the moment when congestion dissipates completely, upstream vehicles will not be affected by accidents. So the influence area under nonbypass condition is travelling distance plus occupied road length during queuing of upstream vehicles under normal condition from the moment of an accident occurrence to queues dissipation.

Based on (4), highway traffic accident influence area under nonbypass condition can be calculated as (5) and as shown in Figure 3.

$$
L=t_{b} \cdot v_{1}+\left|X_{b}\right|,
$$

where $v_{1}$ is the link average speed under normal condition. $t_{b}$ is the moment when queuing vehicles occupy the maximum link length. $X_{b}$ is the distance from the accident spot.

\section{Traffic Accident Influence Area under Bypass Condition}

If drivers consider travel delay of passing through the accident link exceeds bypass threshold, they will choose other 


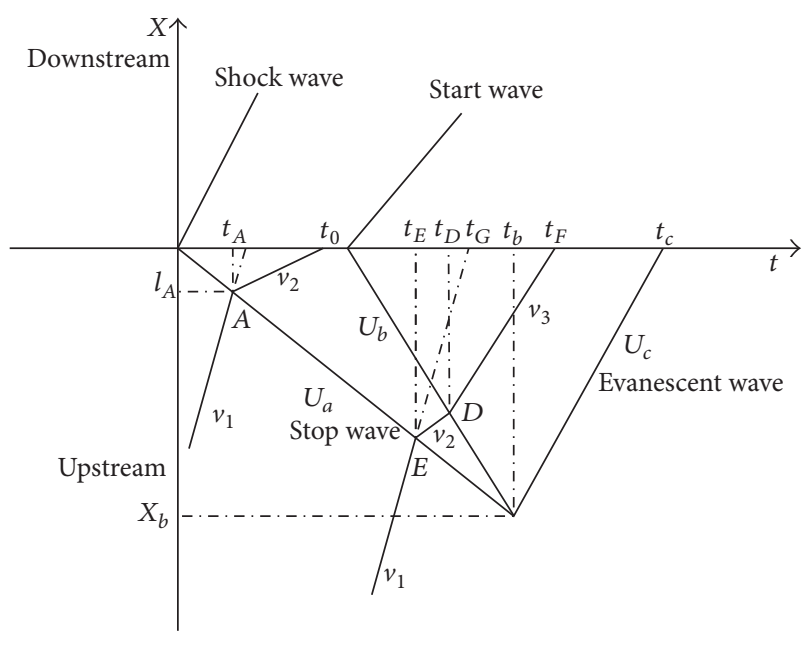

FIGURE 4: Time-spatial running track of vehicles.

routes and the influence area is road network formed by several surrounding links. Thus, bypass route selection of upstream vehicles under accident condition, also known as traffic flow assignment problem, is the keystone of the study.

4.1. Bypass Origin-Destination and Routes. According to (5), upstream vehicles are influenced by the accident within influence area. Upstream vehicles bypass can be seen as route choice behavior with multiple origins and destinations. Suppose that $N_{u}$ and $N_{d}$ are, respectively, the upstream node and the downstream node which are nearest to the accident spot. The origins and destinations of bypass routes are, respectively, all the nodes within the distance $L$ from $N_{u}$ and $N_{d}$. Bypass routes are sets of effective routes between bypass origins and destinations.

4.2. Total Bypass Volume and Volume of Each Bypass Route. Vehicles bypass is a process of traffic flow redistribution; traffic flow assignment is to obtain the distribution of the highway total bypass volume on different routes. Total bypass volume can be determined approximately by the relationship between travel delay and bypass threshold based on traffic wave theory. Before congestion dissipation, time-spatial running track of vehicles whose travel delay exceeds bypass threshold is shown in Figure 4.

In Figure 4, point $A$ is speed change point where the first vehicle's travel delay is equal to threshold, $t_{A}$ is the corresponding duration time, and $l_{A}$ is the distance from the accident spot. $v_{2}$ is the fleet speed after meeting with stop wave. $v_{3}$ is the fleet speed after meeting with start wave. Points $D$ and $E$ are speed change points where the last vehicle's travel delay is equal to threshold, $t_{D}$ and $t_{E}$ are the corresponding duration time, and $t_{F}$ is the duration time after the accident occurrence. $t_{G}$ is the duration time after the accident occurrence if there is no travel delay.
For the first vehicle whose travel delay is equal to threshold, (6) can be established as follows:

$$
\begin{aligned}
\frac{l_{A}}{v_{2}}-\frac{l_{A}}{v_{1}} & =T, \\
t_{A} & =\frac{l_{A}}{U_{a}} .
\end{aligned}
$$

$t_{A}$ is obtained by (6), as show in (7):

$$
t_{A}=\frac{T}{U_{a}}\left(\frac{v_{1} v_{2}}{v_{2}-v_{1}}\right) .
$$

For the last vehicle whose travel delay is equal to threshold, based on the geometric relationship, (8) can be established as follows:

$$
\begin{aligned}
v_{2}\left(t_{D}-t_{E}\right)+v_{3}\left(t_{F}-t_{D}\right) & =U_{a} t_{E}, \\
v_{1}\left(t_{G}-t_{E}\right) & =U_{a} t_{E}, \\
t_{F}-t_{G} & =T, \\
v_{3}\left(t_{F}-t_{D}\right) & =U_{b}\left(t_{D}-t_{0}\right) .
\end{aligned}
$$

$t_{E}, t_{A}$ can be calculated by (8) as

$$
\begin{aligned}
& t_{E}=\frac{t_{D}\left(v_{2}+v_{b}\right)-U_{b} t_{0}}{U_{a}+v_{2}}, \\
& t_{D} \\
& =\frac{v_{1}\left(U_{a}+v_{2}\right) U_{b} t_{0}+T v_{1} v_{3}\left(U_{a}+v_{2}\right)-\left(U_{a}+v_{1}\right) v_{3} U_{b} t_{0}}{U_{a} v_{1} v_{3}+U_{a} U_{b} v_{1}+U_{b} v_{1} v_{2}-U_{b} v_{1} v_{3}-U_{a} v_{2} v_{3}-U_{a} U_{b} v_{3}} .
\end{aligned}
$$

For the time period from accident occurrence to meeting of start wave and queuing wave, assume that $Q_{w 1}$ is wave flow, and the number of vehicles whose travel delay exceeds bypass threshold can be calculated as follows:

$$
N=Q_{w 1}\left(t_{E}-t_{1}\right)
$$

Thus, total bypass flow per unit time within the time period from accident occurrence to evanescent wave formation can be calculated as follows:

$$
Q=\frac{N}{t_{b}}=\frac{Q_{w 1}\left(t_{E}-t_{1}\right)}{t_{b}} .
$$

Improved Logit model $[11,12]$ and assignment algorithm based on routes can be used to calculate bypass flow of each route, algorithm flowchart is shown in Figure 5, and specific algorithm steps are summarized as follows.

Step 1. According to travel delay and bypass threshold, the total bypass volume is determined.

Step 2. Load traffic flow volume to the surrounding road network under normal conditions.

Step 3. Update all link impedance and search bypass routes. 


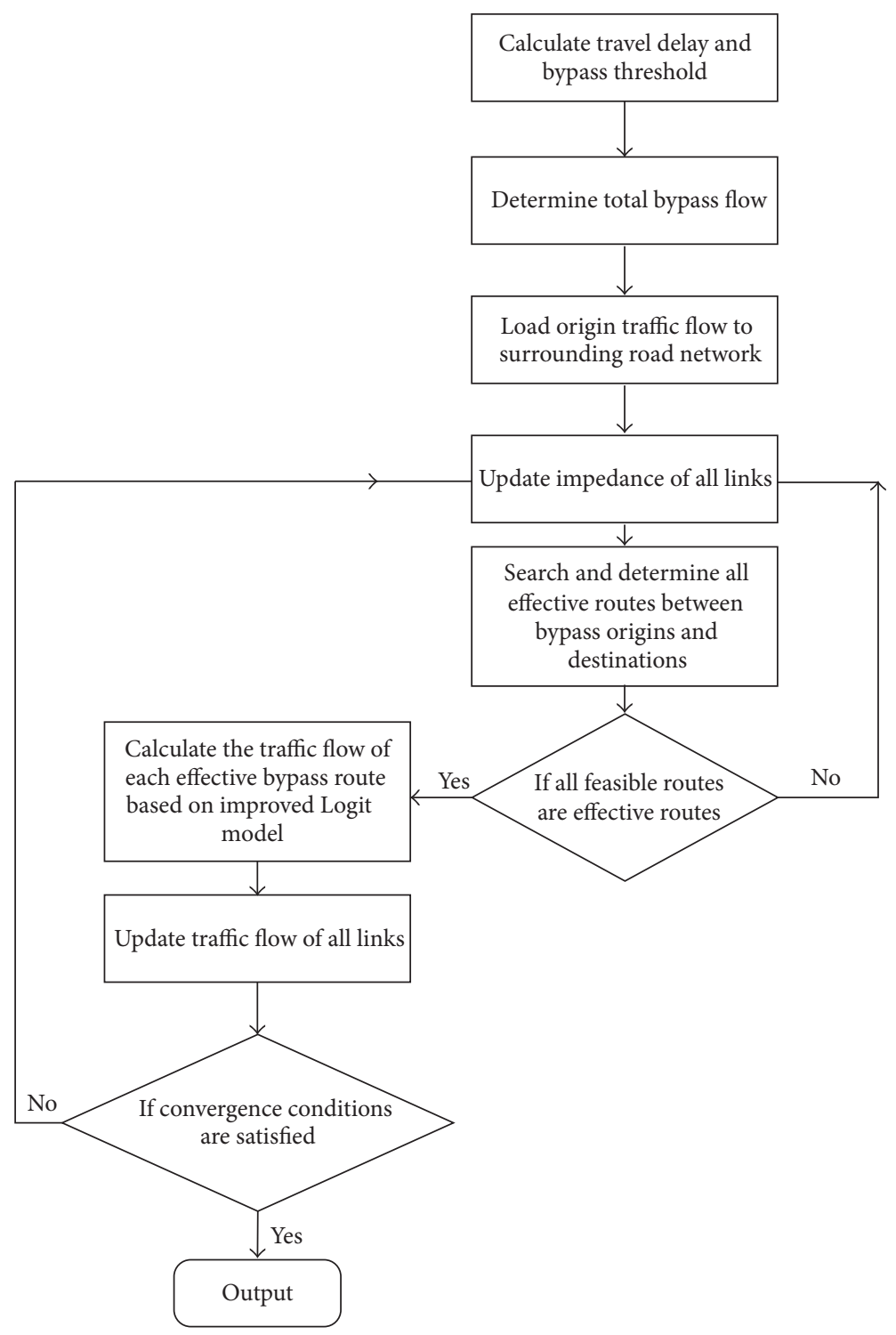

FIGURE 5: Algorithm flowchart.

Step 4. Calculate the selection proportion of each bypass route based on improved Logit model.

Step 5. Calculate traffic flow of each effective route.

Step 6. Calculate traffic flow of each route and link.

Step 7 (convergence tests). Give an acceptable tolerance level $\mu$, if the difference between maximum and minimum travel time of all selected routes does not exceed the tolerance level $\mu$ several times in a row, then stop calculating; otherwise, return to Step 3.

4.3. Influence Area Recognition under Bypass Condition. Vehicles bypass is bound to cause traffic flow variation of accident links surrounding road network traffic, but the variation degree of surrounding link traffic flow is inconsistent. LOS reflects road traffic load status and can be used to divide traffic flow status [13, 14]. So bypass influence degree of surrounding road network is defined referring to service level theory.

(1) If bypass makes LOS decline one or more grades, the link must be influenced.

(2) If bypass does not make LOS decline, whether the link is defined as influenced link needs further consideration, and LOS variation coefficient can be used to determine the influence degree.

Assume that LOS of a link is constant before and after bypass; the influence degree of links can be defined by the following equation:

$$
\begin{aligned}
& \eta_{i}^{j}=\lambda\left(x_{2}-x_{1}\right), \\
& \lambda=1+\frac{x_{2}-C_{\min }^{j}}{C_{\max }^{j}-C_{\min }^{j}},
\end{aligned}
$$




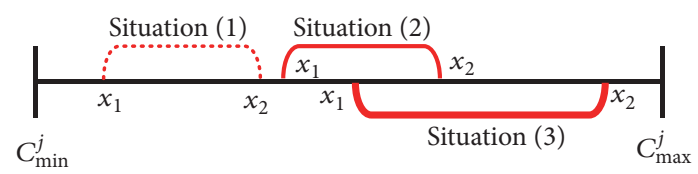

FIGURE 6: Influenced degree analysis of links.

where $\eta_{i}^{j}$ is LOS variation coefficient. $x_{1}$ is saturation of links under no bypass condition. $x_{2}$ is saturation of links after bypass $\left(x_{2}>x_{1}\right) \cdot \lambda$ is correction coefficient of influence degree. $i$ is the link. $j$ is level of service (LOS). $C_{\max }^{j}$ is maximum saturation at $j$-class LOS. $C_{\min }^{j}$ is minimum saturation at $j$-class LOS.

If LOS is constant before and after bypass, the relationship between $x_{1}$ and $x_{2}$ is shown in Figure 6.

In Figure 6, saturation variation in situation (1) and situation (2) is the same; comparing to situation (1), the difference is $x_{1}$ and $x_{2}$ of situation (2) is larger. $x_{1}, x_{2}$, and $x_{2}-$ $x_{1}$ of situation (3) are larger than situation (1) and situation (2). Influence degree sequence of situations is (3)> (2) > (1), which reflects that the greater the load degree varies, the greater the traffic flow status changes and the more severely it is influenced. When saturation variation $x_{2}-x_{1}$ is the same, the greater $x_{1}$ and $x_{2}$, the more severely influenced. This is because the initial saturation is already large, so saturation will be larger while being influenced and is more likely to cause congestion under the premise of the same variation. When $x_{2}=\left(x_{1}+C_{\max }^{j}\right) / 2$, LOS sensitivity coefficient $\eta_{i_{\text {med }}^{j}}^{j}$ is proposed. If $\eta_{i}^{j}>\eta_{i_{\text {med }}^{j}}^{j}$, LOS of link $i$ is in large variation and is regarded as the influenced link; otherwise, it is not regarded as the influenced link. Therefore, highway traffic accident influence area under bypass condition is the road network formed by three types of links: influenced links of highway mainline, links that LOS downgrades, and links that LOS does not downgrade while LOS variation coefficient exceeds LOS sensitivity coefficient.

\section{Case Study}

5.1. Data. A link of Beijing-Kunming highway is selected to study highway traffic accident influence area. In the road network, Beijing-Kunming highway has six nodes: node ID is $1,2,3,4,5$, and 6 . Surrounding parallel links are the following: 7-8-9-10, 9-11-13-14-15, 12-11-13-4, 9-3-18-21, 8-2-17, 16-17-18-4, and 19-20-5-14 (see Figure 7). At the link 3-4, 20 kilometers away from node 4 , a truck rolls over and occupies a lane. Accident duration time $t_{0}=90 \mathrm{~min}$; vehicles' free flow speed $v_{0}=108 \mathrm{~km} / \mathrm{h}$. According to the survey, average travel speed $v_{1}=90 \mathrm{~km} / \mathrm{h}$, traffic flow of link $3-4$ is $Q_{1}=1637 \mathrm{pcu} / \mathrm{h}$, and link 3-4 capacity $Q_{f}=1053 \mathrm{pcu} / \mathrm{h}$. Based on equation of highway basic link capacity, design capacity can be obtained as $Q_{x}=3008 \mathrm{pcu} / \mathrm{h}$. When the accident ends, start traffic flow $Q_{3}=Q_{1}+\left(Q_{1}-Q_{f}\right)=2221 \mathrm{pcu} / \mathrm{h}$ and blocking density $K_{j}=$ $111.4 \mathrm{pcu} / \mathrm{km}$. Taking $85 \%$ quantile as cumulative frequency of bypass threshold acceptance, travel delay threshold is $31 \mathrm{~min}$. Saturation of all links is investigated under normal condition, as shown in Figure 7.

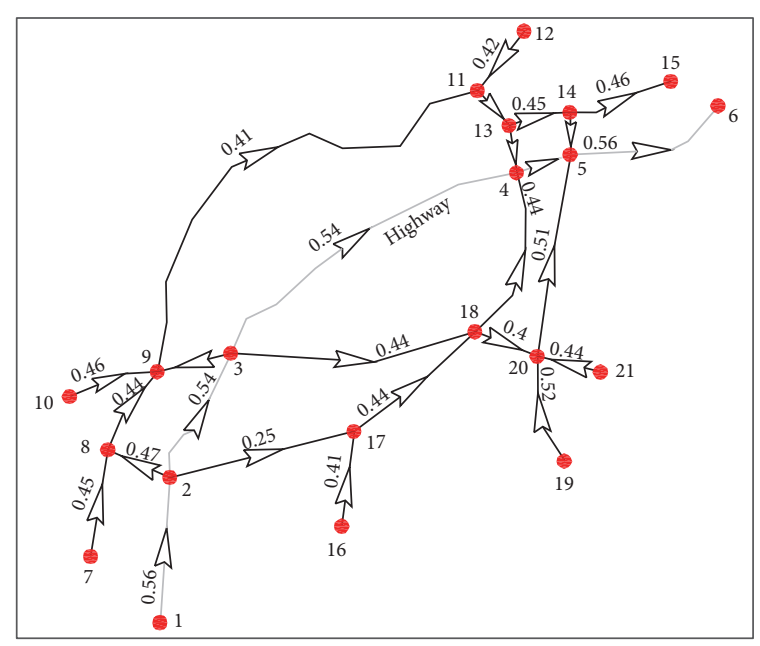

$$
\begin{aligned}
& \text { Beijing-Kunming highway } \\
& \text { Surrounding links } \\
& \text { Node ID }
\end{aligned}
$$

FIgURE 7: Saturation of Beijing-Kunming highway and surrounding links.

5.2. Results. Traffic flow, density, and speed of different conditions can be obtained based on the above data. Queuing wave velocity $U_{a}=7.1 \mathrm{~km} / \mathrm{h}$, start wave velocity $U_{b}=$ $71.1 \mathrm{~km} / \mathrm{h}$, and evanescent wave velocity $U_{c}=36.8 \mathrm{~km} / \mathrm{h}$. According to (3) (5), $t_{b}=99.9 \mathrm{~min}$ and $x_{b}=11.8 \mathrm{~km}$. Therefore, direct influence area on highway mainline can be obtained as $L=162.1 \mathrm{~km}$. Since the accident lasts longer, travel delay of some vehicles exceeds their bypass threshold, which generates bypass. Then, upstream nodes 2 and 3 and downstream nodes 4 and 5 at the accident spot are influenced. According to (6) (11), $t_{A}=50.4 \mathrm{~min}, t_{E}=84.6 \mathrm{~min}$, and $Q=$ $603 \mathrm{pcu} / \mathrm{h}$.

Combined with bypass routes and improved Logit model, using assignment algorithm based route to solve the model, additional traffic flow of each bypass route is obtained, as shown in Table 3.

After traffic flow redistribution, each link load degree is obtained. According to highway service level grading standards [19], LOS of link 9-11 is downgraded from second level to third level. LOS of other surrounding links are not in leapfrog change, so LOS variation coefficient is proposed to determine influence degree. According to (12), $\eta_{i}^{j}$ and $\eta_{i_{\text {med }}^{j}}$ can be calculated, as shown in Table 4.

Under the condition of service levels that are not downgraded, if $\eta_{i}^{j}>\eta_{i_{\text {med }}^{j}}$, LOS of link $i$ is considered in great variation, and the influenced links are, respectively, link ID of 2-8, 3-9, 3-18, 11-13, 13-4, and 18-4. Therefore, the highway accident influence area is road network formed by these influenced links, as shown in Figure 8.

\section{Conclusions and Further Work}

Based on vehicle route choice behavior under accident conditions, the paper analyzed influential factors of bypass 
TABLE 3: Additional traffic flow of each bypass route.

\begin{tabular}{lccc}
\hline Bypass routes & Additional traffic flow & Bypass routes & Additional traffic flow \\
\hline $2-8-9-11-13-4$ & $48 \mathrm{pcu} / \mathrm{h}$ & $3-9-11-13-4$ & $233 \mathrm{pcu} / \mathrm{h}$ \\
$2-17-18-4$ & $29 \mathrm{pcu} / \mathrm{h}$ & $3-18-4$ & $118 \mathrm{pcu} / \mathrm{h}$ \\
$2-8-9-11-13-14-5$ & $37 \mathrm{pcu} / \mathrm{h}$ & $3-9-11-13-14-5$ & $81 \mathrm{pcu} / \mathrm{h}$ \\
$2-17-18-20-5$ & $14 \mathrm{pcu} / \mathrm{h}$ & $3-18-20-5$ & $43 \mathrm{pcu} / \mathrm{h}$ \\
\hline
\end{tabular}

TABLE 4: LOS variation coefficient of links.

\begin{tabular}{lcccc}
\hline Link & Origin & Destination & $\eta_{i}^{j}$ & $\eta_{i_{\text {med }}^{j}}^{j}$ \\
\hline $2-17$ & 2 & 17 & 1.4824 & 1.4882 \\
$2-8$ & 2 & 8 & 1.8710 & 1.8593 \\
$3-9$ & 3 & 9 & 2.1165 & 1.7643 \\
$3-18$ & 3 & 18 & 2.0753 & 1.8118 \\
$8-9$ & 8 & 9 & 1.6172 & 1.7422 \\
$11-13$ & 11 & 13 & 2.3297 & 1.7948 \\
$13-14$ & 13 & 14 & 1.7993 & 1.8172 \\
$13-4$ & 13 & 4 & 2.2616 & 1.8432 \\
$14-5$ & 14 & 5 & 1.5554 & 1.7395 \\
$17-20$ & 17 & 20 & 1.5297 & 1.7312 \\
$18-4$ & 18 & 4 & 1.9194 & 1.7984 \\
$18-20$ & 18 & 20 & 1.6953 & 1.7446 \\
$20-5$ & 20 & 5 & 1.5238 & 1.7141 \\
\hline
\end{tabular}

decision-making and the method to determine bypass threshold. According to the relationship between bypass decision-making index and threshold, accident point route choice behavior of upstream vehicles was divided into two types: bypass and nonbypass. Traffic wave theory was used in determining highway traffic accident influence area under nonbypass condition. For bypass situation, the total bypass volume was determined under the situation of decisionmaking index to be greater than the threshold value. Improved Logit model was used to determine bypass probability and volume of upstream vehicles, and each bypass link volume was also obtained. Assignment algorithms based on routes were proposed to solve the model; comparing with each link service level variation at normal circumstances, influenced links could be determined and the method of determining influence area was established. The paper developed a new idea and method to study highway accident influence area. From the perspective of drivers' bypass behavior, the paper gave full consideration to bypass decision-making influential factors, bypass threshold, and influence degree of the road network, which could provide quantitative methods for determining accident influence area and links.

However, there are several limitations in the present study. First, the paper only studied spatial influence area of highway traffic accident. However, spatial influence area changes over time, and the relationship between time and space should be explored in the following studies. Second, due to the fact that accident occurrence time and accident type will make a complex impact on traffic flow, the inherent relationship between accident factors and influence degree should be further studied, and simulation software can be
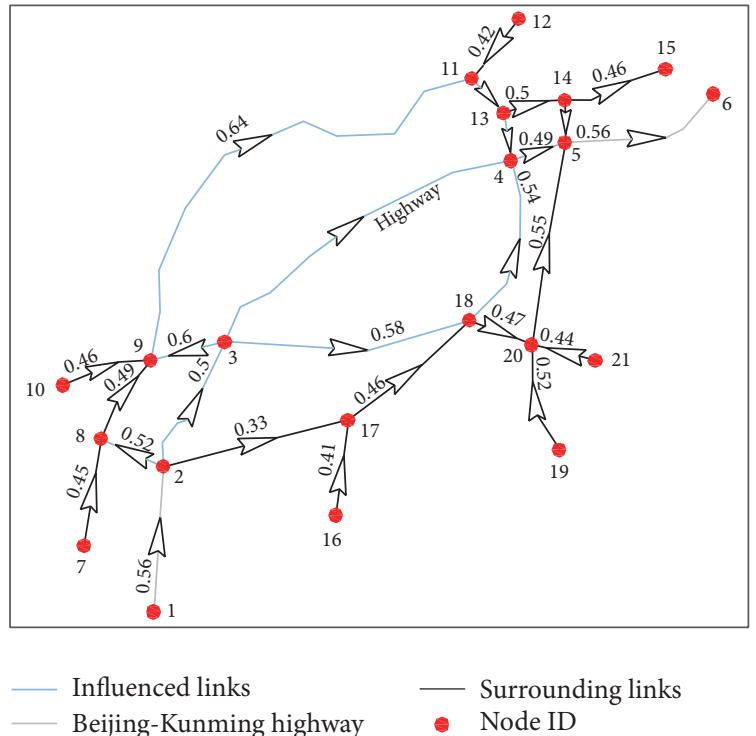

FIGURE 8: Beijing-Kunming highway traffic accident influence area.

used to analyze actual traffic accident cases. Future researches are recommended to improve the deficiencies above so that accident influence area can be determined more reasonably and appropriate measures can be used to deal with the accident, which could guide traffic flow operation efficiently.

\section{Competing Interests}

The authors declare that there is no conflict of interests regarding the publication of this paper.

\section{References}

[1] J. M. Morales, "Analytical procedures for estimating freeway traffic congestion," Public Road, vol. 50, no. 2, pp. 55-61, 1986.

[2] J.-B. Sheu, Y.-H. Chou, and A. Chen, "Stochastic modeling and real-time prediction of incident effects on surface street traffic congestion," Applied Mathematical Modelling, vol. 28, no. 5, pp. 445-468, 2004.

[3] G. F. Newell, "A simplified theory of kinematic waves in highway traffic, part I: general theory," Transportation Research Part B, vol. 27, no. 4, pp. 281-287, 1993.

[4] G. F. Newell, "A simplified theory of kinematic waves in highway traffic, part II: queueing at freeway bottlenecks," Transportation Research Part B, vol. 27, no. 4, pp. 289-303, 1993.

[5] T. W. Lawson, D. J. Lovell, and C. F. Daganzo, "Using inputoutput diagram to determine spatial and temporal extents of 
a queue upstream of a bottleneck," Transportation Research Record, no. 1572, pp. 140-147, 1996.

[6] S. I.-J. Chien, D. G. Goulias, S. Yahalom, and S. M. Chowdhury, "Simulation-based estimates of delays at freeway work zones," Journal of Advanced Transportation, vol. 36, no. 2, pp. 131-156, 2002.

[7] B. Sansó and F. Soumis, "Communication \& transportation network reliability using routing models," IEEE Transactions on Reliability, vol. 40, no. 1, pp. 29-38, 1991.

[8] B. Sansò, "Performability of a congested urban transportation network when accident information is available," Transportation Science, vol. 33, no. 1, pp. 68-79, 1999.

[9] L. Engelson, "On dynamics of traffic queues in a road network with route choice based on real time traffic information," Transportation Research Part C: Emerging Technologies, vol. 11, no. 2, pp. 161-183, 2003.

[10] Z. Y. Cao, Z. Y. Guo, Q. S. Zhang et al., "Research on time and spatial ex-tent of terrible traffic accident on highway," Highway Engineering, vol. 36, no. 6, pp. 56-58, 2011.

[11] Y. H. Chen, R. B. He, and W. Wang, "Amelioration of the Logit model and the solution of the traffic assignment problem," Journal of Chongqing University, vol. 25, no. 12, pp. 95-96, 2002.

[12] J. C. Milton, V. N. Shankar, and F. L. Mannering, "Highway accident severities and the mixed logit model: an exploratory empirical analysis," Accident Analysis \& Prevention, vol. 40, no. 1, pp. 260-266, 2008.

[13] K. Choocharukul, K. C. Sinha, and F. L. Mannering, "User perceptions and engineering definitions of highway level of service: an exploratory statistical comparison," Transportation Research Part A: Policy and Practice, vol. 38, no. 9-10, pp. 677689, 2004.

[14] J. D. Zegeer, M. L. Blogg, K. Nguyen, and M. Vandehey, "Default values for highway capacity and level-of-service analyses," Transportation Research Record: Journal of the Transportation Research Board, vol. 2071, pp. 35-43, 2008.

[15] H. Peng, K.-M. Chen, J.-W. Wang, and Y.-P. Wang, "Travel choice characteristics of transportation corridor of EuropeAsia," Journal of Traffic and Transportation Engineering, vol. 5, no. 1, pp. 120-123, 2005.

[16] H. Zang and G. X. Peng, "A study of link travel time function during inci-dent on urban expressway," Journal of Transportation Systems Engineering and Information Technology, vol. 3, no. 2, pp. 57-59, 2003.

[17] K. Kishi, K. Uchida, and K. Satoh, "Price sensitivity of airfare from the viewpoint of passengers," Infrastructure Planning Review, vol. 16, pp. 187-194, 1999.

[18] K. Kishi, S. Hino, and K. Satoh, "Location planning of elevators at subway stations considering transfer resistance based on passengers' Physical and conscious resistance," Journal of the Eastern Asia Society for Transportation Studies, vol. 5, pp. 32503260, 2003.

[19] China Highway \& Transportation Society, Technical Standard of Highway Engineering, Ministry of Transport of the People's Republic of China, Beijing, China, 2003. 


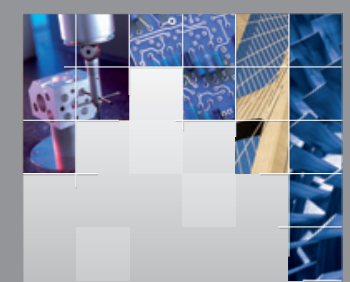

\section{Enfincering}
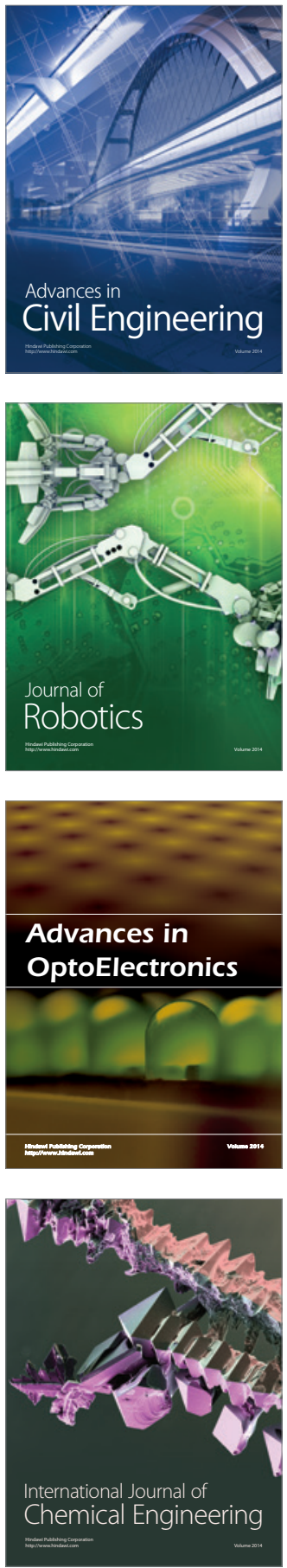

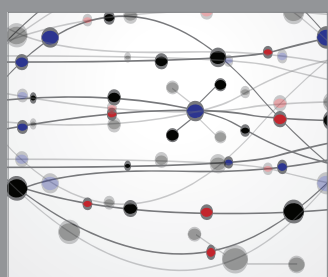

The Scientific World Journal

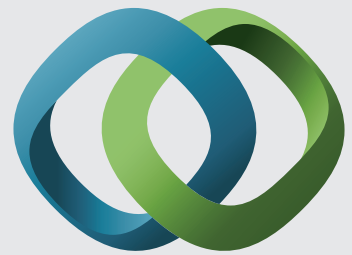

\section{Hindawi}

Submit your manuscripts at

https://www.hindawi.com
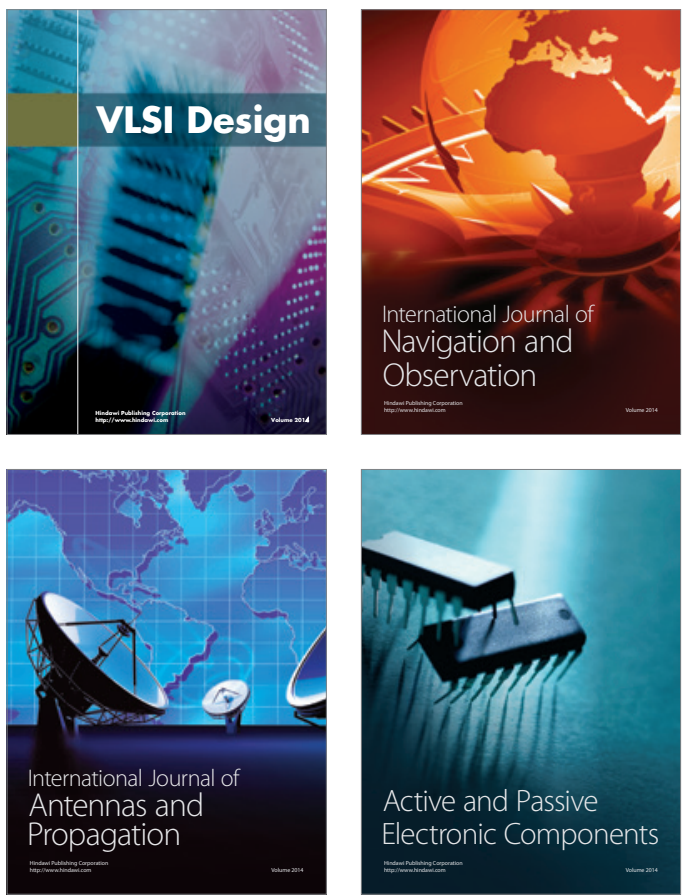
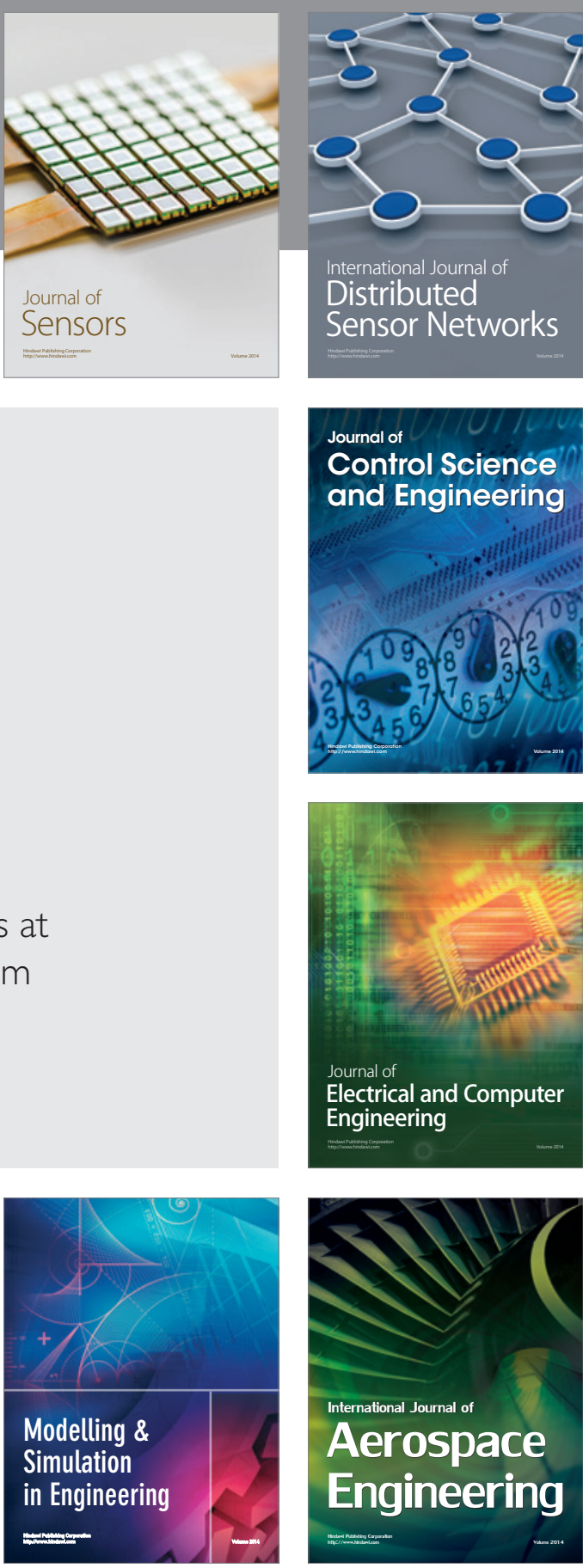

International Journal of

Distributed

Sensor Networks

$-$

Joumal of

Control Science

and Engineering
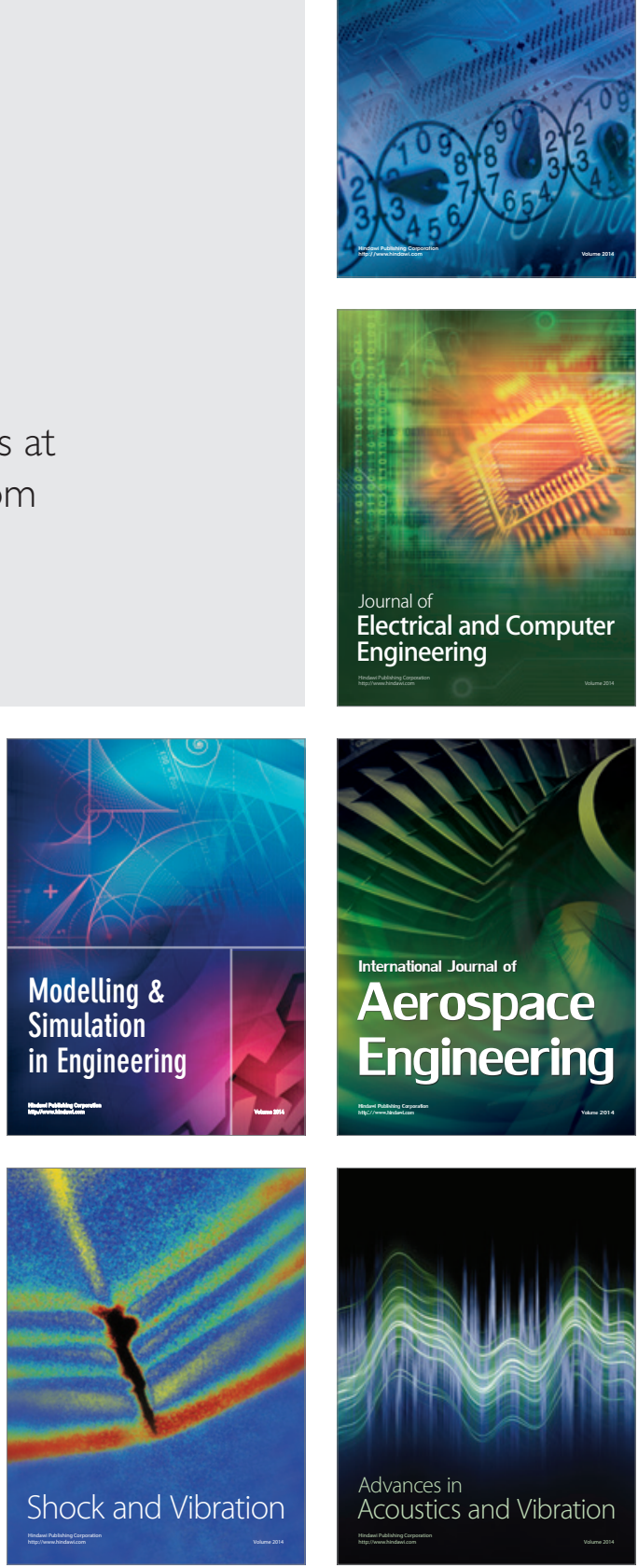